\title{
First Order Hyperpolarizabilities, NPA and Fukui Functions of Cyclohexanone by Density Functional Theory Method
}

\author{
Rubarani P. Gangadharan ${ }^{a, *}$ And S. SAMPATH KRISHNAN ${ }^{b}$ \\ ${ }^{a}$ Department of Physics, Rajalakshmi Engineering College, Thandalam, Chennai-602105, India \\ ${ }^{b}$ Department of Applied Physics, Sri Venkateswara College of Engineering, Chennai-602105, India
}

(Received September 24, 2014; in final form January 27, 2015)

The molecular structure of cyclohexanone was calculated by the B3LYP density functional model with 6$311++\mathrm{G}(\mathrm{d}, \mathrm{p})$ basis set by Gaussian program. The results from natural bond orbital analysis have been analyzed in terms of the hybridization of atoms and the electronic structure of the title molecule. The formation of hydrogen bond was investigated using natural bond orbital calculation. The electron density based local reactivity descriptors such as Fukui functions were calculated. The dipole moment $(\mu)$ and polarizability $(\alpha)$, anisotropy polarizability $(\Delta \alpha)$ and first order hyperpolarizability $\left(\beta_{\text {tot }}\right)$ of the molecule have been reported. Thermodynamic properties of the title compound were calculated at different temperatures.

DOI: $10.12693 /$ APhysPolA.127.748

PACS: 61.30.-v, 78.30.Jw, 31.15.Ew

\section{Introduction}

Cyclohexanone is a colorless, mobile liquid with an odor similar to that of pepper mint and acetone $[1,2]$. It was first prepared by the dry distillation of calcium pimelate and later by Bouveault by the catalytic dehydrogenation of cyclohexanol [3]. It is used as a solvent in insecticides, wood stains, paint and varnish removers, spot removers, cellulosics, and natural and synthetic resins and lacquers. The most important use of cyclohexanone is as a chemical intermediate in nylon manufacture: $97 \%$ of all cyclohexanone output is used either to make caprolactam for nylon-6 or adipic acid for nylon66. Cyclohexanone is also used as a solvent and thinner for lacquers, especially those containing nitrocellulose or vinyl chloride polymer and copolymers and as a general solvent for synthetic resins and polymers. Cyclohexanone is used as a building block in the synthesis of many organic compounds, such as pharmaceuticals, insecticides, and herbicides $[4,5]$. The objective of the present work is to investigate the nature of bonding in cyclohexanone (Fig. 1) by using natural bond orbital (NBO) analysis. We have shown that the results from NBO calculations can provide the detailed insight into the electronic structure of molecule.

\section{Computational methods}

All the calculations were performed using the Gaussian $03 \mathrm{~W}$ software package [6] and Gauss-view molecular visualization program package [7]. The calculations of systems containing $\mathrm{C}, \mathrm{H}$, and $\mathrm{O}$ is described by the standard 6-311++G(d,p) basis set function of the density functional theory (DFT) $[8,9]$. Geometry optimization

\footnotetext{
* corresponding author; e-mail:

rubarani.p.gangadharan@rajalakshmi.edu.in
}

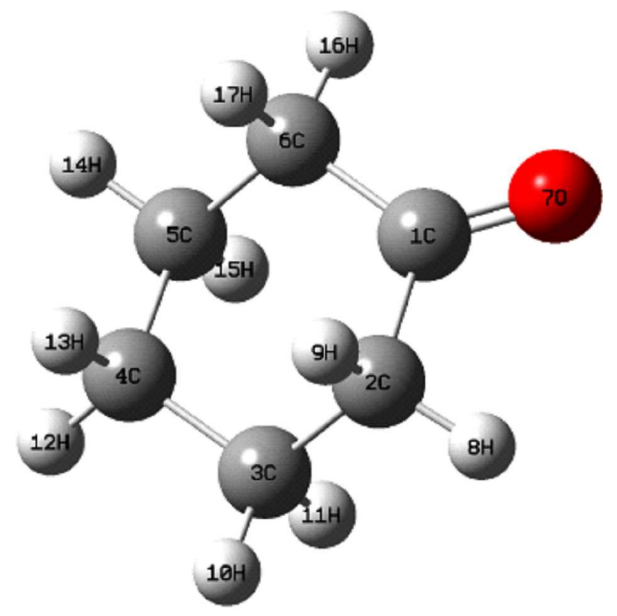

Fig. 1. The atom numbering system for cyclohexanone.

was performed utilizing Becker's hybrid three-parameter exchange functional and the nonlocal correlation functional of Lee, Yang, and Parr (B3LYP) [10]. The population analysis has also been performed by the natural bond orbital method [11] at B3LYP/6-31G(d,p) and $6-311++\mathrm{G}(\mathrm{d}, \mathrm{p})$ level of theory using NBO program under Gaussian 03 program package.

Natural bond orbital analysis stresses the role of intermolecular orbital interaction in the complex, particularly charge transfer. This is carried out by considering all possible interactions between filled donor and empty acceptor NBOs and estimating their energetic importance by second-order perturbation theory. For each donor NBO $(i)$ and acceptor NBO $(j)$, the stabilization energy $E^{(2)}$ associated with electron delocalization between donor and acceptor is estimated as

$$
E^{(2)}=q_{i} \frac{\left(F_{i, j}\right)^{2}}{\varepsilon_{j}-\varepsilon_{i}},
$$

where $q_{i}$ is the orbital occupancy, $\varepsilon_{i}, \varepsilon_{j}$ are diagonal 
elements and $F_{i, j}$ is the off-diagonal NBO Fock matrix element.

\section{Results and discussion}

\subsection{NPA atomic charges}

NPA stands for natural population analysis and is based on the NBO scheme. Natural bond analysis classifies and localizes orbitals into three distinct groups: non-bonding natural atomic orbitals (NAOs), orbitals involved in bonding and antibonding (NBOs), and Rydberg type orbitals. The Rydberg type orbitals and NAOs are made up of basis sets of single atoms and the NBOs are a combination of basis set atomic orbitals of two atoms. This is similar to our notion of core electrons, lone pairs of electrons, and valence electrons, and works under the assumption that only the bonding orbitals should be made by combinations of two atoms' basis sets. Based on this model of electron partitioning, NPA then treats the NBOs as the Mulliken method treats all the orbitals. This method differentiates between the orbitals that will overlap to form a bond and those that are too near the core of an atom to be involved in bonding. This results in convergence of atomic partial charge to a stable value as the basis set size is increased. NPA also tends to predict larger charges than several other population analysis methods, so like Mulliken charges NPA is best used for comparing differences rather than determining absolute atomic charges.

\section{TABLE I}

NPA charges calculated by B3LYP/6-31G(d,p) and B3LYP $/ 6-311++\mathrm{G}(\mathrm{d}, \mathrm{p})$ methods.

\begin{tabular}{c|c|c}
\hline \hline Atom No. & $\begin{array}{c}\text { B3LYP/ } \\
6-31 \mathrm{G}(\mathrm{d}, \mathrm{p})\end{array}$ & $\begin{array}{c}\text { B3LYP/ } \\
6-311++\mathrm{G}(\mathrm{d}, \mathrm{p})\end{array}$ \\
\hline C1 & 0.264 & 0.588 \\
C2 & -0.497 & -0.477 \\
C3 & -0.423 & -0.382 \\
C4 & -0.426 & -0.386 \\
C5 & -0.423 & -0.382 \\
C6 & -0.497 & -0.476 \\
O7 & -0.757 & -0.556 \\
H8 & 0.207 & 0.225 \\
H9 & 0.119 & 0.214 \\
H10 & 0.175 & 0.205 \\
H11 & 0.19 & 0.194 \\
H12 & 0.193 & 0.206 \\
H13 & 0.183 & 0.188 \\
H14 & 0.175 & 0.205 \\
H15 & 0.19 & 0.194 \\
H16 & 0.207 & 0.225 \\
H17 & 0.119 & 0.214
\end{tabular}

NPA charges calculated by B3LYP methods are collected in Table I. It can be clearly shown that the carbon atom attached with oxygen atom has positive charge whereas other carbon atoms attached to hydrogen atoms have negative charge. It is worthy to mention that $\mathrm{C} 1$ alone of title molecule exhibits positive charge while $\mathrm{C} 2, \mathrm{C} 3, \mathrm{C} 4, \mathrm{C} 5, \mathrm{C} 6$ atoms exhibit negative charges. Oxygen has a maximum negative charge value of about -0.757 . However all the hydrogen atoms exhibit a net positive charges. The presence of large negative charge on $\mathrm{O}$ atom and net positive charge on $\mathrm{H}$ atom may suggest the formation of intramolecular interaction in solid forms [12].

\subsection{NBO analysis}

NBO analysis provides an efficient method for studying intra and intermolecular bonding and interaction among bonds, and also provides a convenient basis for investigation charge transfer or conjugative interactions in molecular system [13]. Some electron donor orbital, acceptor orbital and the interacting stabilization energy resulting from the second order micro-disturbance theory are reported $[14,15]$. The larger the $E(2)$ value, the more intensive is the interaction between electron donors and the greater the extent of conjugation of the whole system. Delocalization of occupation between occupied Lewis type (bond or lone pair) NBO orbital's and formally unoccupied (antibonding or Rydberg) non Lewis NBO orbital's correspond to a stabling donoracceptor interaction. NBO analysis was performed on the molecule at the DFT/B3LYP/6-311++G(d,p) level in order to elucidate the intra molecular rehybridization and delocalization of occupation within the molecule. The molecular interaction is formed by the orbital overlap between $\sigma(\mathrm{C}-\mathrm{C})$ and $\sigma^{*}(\mathrm{C}-\mathrm{C})$ bond orbital which results in intramolecular charge (ICT) causing stabilization of the system. These interactions are observed as increase in occupation in $\mathrm{C}-\mathrm{C}$ antibonding orbital that weakens the respective bonds. The occupation of conjugated double as well as the single bond of the conjugated ring $(\approx 1.9 e)$ clearly demonstrates strong delocalization inside the molecule.

Table II lists the calculated occupancies of natural orbitals. Three classes of NBOs are included, the Lewistype ( $\sigma$ and $\pi$ bonding or lone pair) orbitals, the valence non-Lewis (acceptors formally unfilled) orbitals and the Rydberg NBOs, which originate from orbitals outside the atomic valence shell. The calculated natural hybrids on atoms are also given in this Table II. As seen from Table II, the $\sigma(\mathrm{C} 1-\mathrm{C} 2)$ bond is formed from $s p^{1.972}$ hybrid on carbon (which is the mixture of $34.25 \% s, 65.71 \% p$, and $0.04 \% d$ atomic orbitals). On the other hand, $\sigma(\mathrm{C} 4-\mathrm{H} 12)$ bond is formed from a $s p^{3.47}$ hybrid on hydrogen (which is the mixture of $22.35 \% \mathrm{~s}$, $77.59 \% p$, and $0.06 \% d$ orbitals $)$. The $\pi(\mathrm{C} 1-\mathrm{O} 7)$ is formed from $s p^{2.18}$ hybrid on oxygen (which is the mixture of $31.43 \% s, 68.40 \% p$, and $0.18 \% d)$.

In Table III the perturbation energies of donoracceptor interactions are presented. In our title molecule cyclohexanone $\sigma(\mathrm{C} 2-\mathrm{H} 9) \rightarrow \pi *(\mathrm{C} 1-\mathrm{O} 7)$ and $\sigma(\mathrm{C} 6-\mathrm{H} 17) \rightarrow \pi *(\mathrm{C} 1-\mathrm{O} 7)$ has $6.26 \mathrm{~kJ} / \mathrm{mol}$ and hence they give strong stabilization to the structure. From Table II it is noted that the maximum occupancies $1.98263,1.98120,1.98356,1.98010$ are obtained for 
TABLE II

Occupancy of natural orbitals (NBOs) and hybrids of cyclohexanone calculated by B3LYP method with 6-311 $++\mathrm{G}(\mathrm{d}, \mathrm{p})$ basis set for $\mathrm{C}, \mathrm{H}$ and $\mathrm{O}$ atoms.

\begin{tabular}{|c|c|c|c|}
\hline $\begin{array}{l}\text { Donor Lewis } \\
\text { type }^{a} \text { NBOs }\end{array}$ & Occupation & Hybrid $^{b}$ & $\mathrm{NAO}(\%)^{c}$ \\
\hline$\sigma \mathrm{C} 1-\mathrm{C} 2$ & 1.98263 & $s p^{1.92}$ & $s(34.25 \%) p(65.71 \%) d(0.04 \%)$ \\
\hline$\sigma \mathrm{C} 1-\mathrm{O} 7$ & 1.99612 & $s p^{2.18}$ & $s(31.43 \%) p(68.40 \%) d(0.18 \%)$ \\
\hline$\sigma \mathrm{C} 2-\mathrm{H} 8$ & 1.9812 & $s p^{3.23}$ & $s(23.63 \%) p(76.31 \%) d(0.06 \%)$ \\
\hline$\sigma \mathrm{C} 3-\mathrm{H} 1$ & 1.97928 & $s p^{3.58}$ & $s(21.80 \%) p(78.13 \%) d(0.07 \%)$ \\
\hline$\sigma \mathrm{C} 4-\mathrm{H} 1$ & 1.97828 & $s p^{3.47}$ & $s(22.35 \%) p(77.59 \%) d(0.06 \%)$ \\
\hline$\sigma \mathrm{C} 6-\mathrm{H} 1$ & 1.95971 & $s p^{3.66}$ & $s(21.45 \%) p(78.48 \%) d(0.07 \%)$ \\
\hline $\mathrm{LP}(1) \mathrm{O} 7$ & 1.97691 & $s p^{0.75}$ & $s(58.07 \%) p(42.91 \%) d(0.02 \%)$ \\
\hline$\sigma^{*} \mathrm{C} 1-\mathrm{C}$ & 0.06204 & $s p^{1.92}$ & $s(34.25 \%) p(65.71 \%) d(0.04 \%)$ \\
\hline$\sigma^{*} \mathrm{C} 1-\mathrm{O}$ & 0.01368 & $s p^{2.18}$ & $s(31.43 \%) p(68.40 \%) d(0.18 \%)$ \\
\hline$\sigma^{*} \mathrm{C} 2-\mathrm{H}$ & 0.01047 & $s p^{3.23}$ & $s(23.63 \%) p(76.31 \%) d(0.06 \%)$ \\
\hline$\sigma^{*} \mathrm{C} 3-\mathrm{H} 11$ & 0.01731 & $s p^{3.58}$ & $s(21.80 \%) p(78.13 \%) d(0.07 \%)$ \\
\hline$\sigma^{*} \mathrm{C} 4-\mathrm{H} 12$ & 0.01207 & $s p^{3.47}$ & $s(22.35 \%) p(77.59 \%) d(0.06 \%)$ \\
\hline$\sigma^{*} \mathrm{C} 6-\mathrm{H} 17$ & 0.01446 & $s p^{3.66}$ & $s(21.45 \%) p(78.48 \%) d(0.07 \%)$ \\
\hline
\end{tabular}

$\sigma(\mathrm{C} 1-\mathrm{C} 2), \sigma(\mathrm{C} 2-\mathrm{H} 8), \sigma(\mathrm{C} 3-\mathrm{C} 4)$ and $\sigma(\mathrm{C} 5-\mathrm{H} 14)$, respectively. Therefore, the results suggest that the $\sigma(\mathrm{C} 1-\mathrm{C} 2)$, $\sigma(\mathrm{C} 2-\mathrm{H} 8), \sigma(\mathrm{C} 3-\mathrm{C} 4)$, and $\sigma(\mathrm{C} 5-\mathrm{H} 14)$ are essentially controlled by the $p$-character of the hybrid orbitals.

The same kind of interaction is calculated in the same kind of interaction energy, related to the resonance in the molecule, where electron donating from $\sigma(\mathrm{O} 7)$ to $\sigma^{*}(\mathrm{C} 1-\mathrm{C} 2)$ shows less stabilization $1.88 \mathrm{~kJ} / \mathrm{mol}$ and further $\pi(\mathrm{O} 7)$ to $\sigma^{*}(\mathrm{C} 1-\mathrm{C} 2)$ leads to strong stabilization energy of $19.88 \mathrm{~kJ} / \mathrm{mol}$. The strong intra-molecular hyper conjugation interaction of the $\sigma$ and the $\pi$ electrons of $\mathrm{C}-\mathrm{H}$ to the anti $\mathrm{C}-\mathrm{H}$ bond in the ring lead to stabilization of some part of the ring as evident from Table III.

\subsection{Fukui functions}

DFT is one of the important tools of quantum chemistry to understand popular chemical concepts such as electronegativity, electron affinity, chemical potential and ionisation potential. In order to solve the negative Fukui function problem, different attempts have been made by various groups [16]. Kolandaivel et al. [17] introduced the atomic descriptor to determine the local reactive sites of the molecular system. In the present study, the AM1-optimised molecular geometry was utilized in single-point energy calculations, which have been performed at the DFT for the anions and cations of the conformers using the ground state with doublet multiplicity. The individual atomic charges calculated by NPA and Mulliken population analysis (MPA) have been used to calculate the Fukui function. Table IV shows the $f_{k}^{0}, f_{k}^{+}$and $f_{k}^{-}$values for the title molecule calculated by NPA and MPA gross charges at DFT level of theory with the basis set $(\mathrm{B} 3 \mathrm{LYP} / 6-311 \mathrm{G}++(\mathrm{d}, \mathrm{p}))$. It has been found that both NPA and MPA scheme methods predict that the oxygen atom $\mathrm{O} 7$ has a higher $f_{k}^{+}$value
TABLE III

Second order perturbation theory analysis of Fock matrix in NBO basis in cyclohexanone.

\begin{tabular}{|c|c|c|c|c|c|c|c|c|}
\hline $\begin{array}{c}\text { Donor } \\
(i)\end{array}$ & Type & $\begin{array}{l}\text { Occu- } \\
\text { pation }\end{array}$ & $\begin{array}{c}\text { Acceptor } \\
(j)\end{array}$ & $\begin{array}{c}\text { Ty- } \\
\text { pe }\end{array}$ & \begin{tabular}{|c|} 
Occu- \\
pation \\
$(e)$
\end{tabular} & {$\left[\begin{array}{c}E(2)^{a} \\
{[\mathrm{~kJ} / \mathrm{mol}]}\end{array}\right.$} & $\begin{array}{c}E(j) \\
-E(i)^{b}\end{array}$ & $F(i, j)^{c}$ \\
\hline \multirow[t]{2}{*}{$\mathrm{C} 1-\mathrm{C} 2$} & \multirow[t]{2}{*}{$\bar{\sigma}$} & \multirow[t]{2}{*}{1.98263} & C3-H10 & $\sigma^{*}$ & 0.01275 & 1.53 & 1.03 & 0.035 \\
\hline & & & C6-H16 & $\sigma^{*}$ & 0.01047 & 1.18 & 1.03 & 0.031 \\
\hline \multirow[t]{2}{*}{$\mathrm{C} 2-\mathrm{C} 3$} & \multirow[t]{2}{*}{$\sigma$} & \multirow[t]{2}{*}{1.97394} & $\mathrm{C} 1-\mathrm{O} 7$ & $\sigma^{*}$ & 0.01368 & 2.14 & 1.22 & 0.046 \\
\hline & & & $\mathrm{C} 1-\mathrm{O} 7$ & $\pi^{*}$ & 0.08186 & 1.97 & 0.63 & 0.032 \\
\hline \multirow[t]{2}{*}{$\mathrm{C} 2-\mathrm{H} 8$} & \multirow[t]{2}{*}{$\sigma$} & \multirow[t]{2}{*}{1.9812} & $\mathrm{C} 1-\mathrm{C} 6$ & $\sigma^{*}$ & 0.06204 & 3.49 & 0.89 & 0.05 \\
\hline & & & $\mathrm{C} 3-\mathrm{C} 4$ & $\sigma^{*}$ & 0.01376 & 2.67 & 0.88 & 0.043 \\
\hline \multirow[t]{3}{*}{$\mathrm{C} 2-\mathrm{H} 9$} & \multirow[t]{3}{*}{$\sigma$} & \multirow[t]{3}{*}{1.95969} & $\mathrm{C} 1-\mathrm{O} 7$ & $\sigma^{*}$ & 0.01368 & 1.34 & 1.11 & 0.035 \\
\hline & & & $\mathrm{C} 1-\mathrm{O} 7$ & $\pi^{*}$ & 0.08186 & 6.26 & 0.52 & 0.052 \\
\hline & & & C3-H11 & $\sigma^{*}$ & 0.01731 & 2.76 & 0.88 & 0.044 \\
\hline \multirow[t]{2}{*}{$\mathrm{C} 3-\mathrm{C} 4$} & \multirow[t]{2}{*}{$\sigma$} & \multirow[t]{2}{*}{1.98356} & $\mathrm{C} 2-\mathrm{H} 8$ & $\sigma^{*}$ & 0.01047 & 1.65 & 1.01 & 0.036 \\
\hline & & & C5-H14 & $\sigma^{*}$ & 0.01274 & 1.65 & 1.01 & 0.036 \\
\hline \multirow[t]{2}{*}{$\mathrm{C} 3-\mathrm{H} 11$} & \multirow[t]{2}{*}{$\sigma$} & \multirow[t]{2}{*}{1.97928} & C2-H9 & $\sigma^{*}$ & 0.01447 & 2.71 & 0.87 & 0.043 \\
\hline & & & $\mathrm{C} 4-\mathrm{H} 13$ & $\sigma^{*}$ & 0.01784 & 2.97 & 0.87 & 0.46 \\
\hline \multirow[t]{2}{*}{$\mathrm{C} 4-\mathrm{H} 12$} & \multirow[t]{2}{*}{$\sigma$} & \multirow[t]{2}{*}{1.97828} & $\mathrm{C} 2-\mathrm{C} 3$ & $\sigma^{*}$ & 0.01383 & 3.13 & 0.86 & 0.047 \\
\hline & & & $\mathrm{C} 5-\mathrm{C} 6$ & $\sigma^{*}$ & 0.01382 & 3.13 & 0.86 & 0.047 \\
\hline \multirow[t]{2}{*}{$\mathrm{C} 4-\mathrm{H} 13$} & \multirow[t]{2}{*}{$\sigma$} & \multirow[t]{2}{*}{1.97902} & C3-H11 & $\sigma^{*}$ & 0.01731 & 2.89 & 0.88 & 0.045 \\
\hline & & & C5-H15 & $\sigma^{*}$ & 0.01731 & 2.89 & 0.88 & 0.045 \\
\hline \multirow[t]{2}{*}{ C5-H14 } & \multirow[t]{2}{*}{$\sigma$} & \multirow[t]{2}{*}{1.9801} & $\mathrm{C} 1-\mathrm{C} 6$ & $\sigma^{*}$ & 0.06204 & 2.75 & 0.88 & 0.044 \\
\hline & & & $\mathrm{C} 3-\mathrm{C} 4$ & $\sigma^{*}$ & 0.01376 & 2.87 & 0.88 & 0.045 \\
\hline \multirow[t]{2}{*}{ C6-H16 } & \multirow[t]{2}{*}{$\sigma$} & \multirow[t]{2}{*}{1.9812} & $\mathrm{C} 1-\mathrm{C} 2$ & $\sigma^{*}$ & 0.06204 & 3.49 & 0.89 & 0.05 \\
\hline & & & $\mathrm{C} 4-\mathrm{C} 5$ & $\sigma^{*}$ & 0.01376 & 2.67 & 0.88 & 0.043 \\
\hline $\mathrm{C} 6-\mathrm{H} 17$ & $\sigma$ & 1.95971 & $\mathrm{C} 1-\mathrm{O} 7$ & $\sigma^{*}$ & 0.01368 & 1.34 & 1.11 & 0.035 \\
\hline & & & $\mathrm{C} 1-\mathrm{O} 7$ & $\pi^{*}$ & 0.08186 & 6.26 & 0.52 & 0.052 \\
\hline O7 & $\sigma$ & 1.97691 & $\mathrm{C} 1-\mathrm{C} 2$ & $\sigma^{*}$ & 0.06204 & 1.88 & 1.07 & 0.04 \\
\hline & & & $\mathrm{C} 1-\mathrm{C} 6$ & $\sigma^{*}$ & 0.06204 & 1.88 & 1.07 & 0.04 \\
\hline O7 & $\pi$ & 1.89261 & $\mathrm{C} 1-\mathrm{C} 2$ & $\sigma^{*}$ & 0.06204 & 19.88 & 0.65 & 0.103 \\
\hline & & & $\mathrm{C} 1-\mathrm{C} 6$ & $\sigma^{*}$ & 0.06204 & 19.88 & 0.65 & 0.103 \\
\hline (2) & ns & & hyper & & . & . & (sta & iliza- \\
\hline
\end{tabular}

for nucleophilic attack. From the values reported in the Table IV the reactivity order for the electrophilic case was $\mathrm{H} 12>\mathrm{H} 10>\mathrm{H} 14$ for MPA analysis. On the other hand, for nucleophilic attack $\mathrm{O} 11$ has greater reactivity value. The attack for radical case was $\mathrm{H} 12>\mathrm{H} 10>\mathrm{H} 14$ for MPA. If one compares the three kinds of attacks, it is possible to observe that the electrophilic attack has bigger reactivity compared to the nucleophilic and radial attack.

\subsection{First order hyperpolarizability calculations}

Polarizabilities and hyperpolarizabilities characterize the response of a system in an applied electric field [18]. They determine not only the strength of molecular interactions as well as the cross-sections of different scattering and collision processes, but also the non-linear optical properties (NLO) of the system [19, 20]. In order to investigate the relationships among photocurrent generation, molecular structures and NLO, the polarizabilities and hyperpolarizabilities of title compound was calculated using B3LYP/6-31G(d,p) and B3LYP /6-311++G(d,p) based on the finite-field approach. The first order hyperpolarizability $(\beta)$ of title molecule along with related properties $\left(\mu, \alpha\right.$, and $\left.\alpha_{0}\right)$ are reported in Table $\mathrm{V}$. The calculated value of dipole moment was found to be $1.2107 \mathrm{D}$ at $\operatorname{B} 3 \mathrm{LYP} / 6-31 \mathrm{G}(\mathrm{d}, \mathrm{p})$ and 1.3651 at 
TABLE IV

Condensed Fukui functions calculated by B3LYP/ $6-311++\mathrm{G}(\mathrm{d}, \mathrm{p})$ from NPA and MPA schemes.

\begin{tabular}{c|c|c|c|c|c|c}
\hline \hline \multirow{2}{*}{ Atoms } & \multicolumn{3}{|c|}{ MPA } & \multicolumn{3}{c}{ NPA } \\
\cline { 2 - 7 } & $f_{k}^{+}$ & $f_{k}^{-}$ & $f_{k}^{0}$ & $f_{k}^{+}$ & $f_{k}^{-}$ & $f_{k}^{0}$ \\
\hline C1 & 0.2491 & 0.131 & 0.3672 & -0.2845 & 0.2757 & -0.0044 \\
C2 & -0.4105 & -0.0614 & -0.7596 & 0.3209 & -0.2395 & 0.0407 \\
C3 & -0.2796 & -0.0526 & -0.5066 & 0.2001 & -0.1948 & 0.0027 \\
C4 & -0.5465 & -0.0084 & -1.0845 & 0.1909 & -0.1948 & -0.002 \\
C5 & -0.2795 & -0.0526 & -0.5063 & 0.2001 & -0.1948 & 0.0027 \\
C6 & -0.4105 & -0.0614 & -0.7596 & 0.3208 & -0.2395 & 0.0407 \\
O7 & 0.2347 & 0.3753 & 0.094 & 0.8317 & -0.2717 & 0.28 \\
H8 & 0.0866 & 0.0673 & 0.1059 & -0.0915 & 0.142 & 0.0149 \\
H9 & 0.3012 & 0.0979 & 0.5044 & -0.0757 & 0.105 & 0.0147 \\
H10 & 0.4328 & 0.0799 & 0.7857 & -0.0574 & 0.1022 & 0.0224 \\
H11 & 0.0692 & 0.064 & 0.0743 & -0.0816 & 0.1033 & 0.0109 \\
H12 & 0.4911 & 0.0566 & 0.8255 & -0.0837 & 0.1064 & 0.0114 \\
H13 & 0.1723 & 0.0552 & 0.2894 & -0.0839 & 0.0899 & 0.003 \\
H14 & 0.4327 & 0.0799 & 0.7855 & -0.0574 & 0.1022 & 0.0224 \\
H15 & 0.0692 & 0.064 & 0.0743 & -0.0816 & 0.1033 & 0.0109 \\
H16 & 0.0866 & 0.0673 & 0.1058 & -0.0916 & 0.1212 & 0.0148 \\
H17 & 0.3011 & 0.0978 & 0.5044 & -0.0757 & 0.1049 & 0.0146
\end{tabular}

6-311++ $\mathrm{G}(\mathrm{d}, \mathrm{p})$. In addition to the isotropic polarizabilities and polarizabilities anisotropy invariant were also calculated. The calculated anisotropy of the polarizability $\alpha$ of cyclohexanone is 119.39 at B3LYP/ 6-31G(d,p) and 137.01 a.u. at B3LYP $/ 6-311++\mathrm{G}(\mathrm{d}, \mathrm{p})$ level. The B3LYP/6-31G $(\mathrm{d}, \mathrm{p})$ calculated first order hyperpolarizability value $\left(\beta_{0}\right)$ of cyclohexanone is equal to $5.239 \times 10^{-31}$ esu. Total dipole moment of title molecule is slightly smaller than those of urea and first order hyperpolarizability of title molecule is approximately four times greater than those of urea $(1.3 \times$ $10^{-31} \mathrm{esu}$ ). This result indicates the nonlinearity of the title molecule.

TABLE V

The B3LYP $/ 6-31 \mathrm{G}(\mathrm{d}, \mathrm{p})$ and $6-311 \mathrm{G}++(\mathrm{d}, \mathrm{p})$ calculated electric dipole moments (Debye), polarizability (a.u), $\beta$ components and $\beta_{\text {tot }}\left(10^{-31}\right)$ esu value of cyclohexanone.

\begin{tabular}{c|c|c|c|c|c}
\hline \hline $\begin{array}{c}\text { Para- } \\
\text { meters }\end{array}$ & $\begin{array}{c}\mathrm{B} 3 \mathrm{LYP} / \\
6-31 \\
\mathrm{G}(\mathrm{d}, \mathrm{p})\end{array}$ & $\begin{array}{c}\mathrm{B} 3-311++ \\
\mathrm{G}(\mathrm{d}, \mathrm{p})\end{array}$ & $\begin{array}{c}\text { Para- } \\
\text { meters }\end{array}$ & $\begin{array}{c}\text { B3LYP/ } \\
6-31\end{array}$ & $\begin{array}{c}\text { B3LYP/ } \\
6-311++ \\
\mathrm{G}(\mathrm{d}, \mathrm{p})\end{array}$ \\
\hline$\mu_{x}$ & 1.2 & 1.353 & $\beta_{x x x}$ & 37.87 & 37.556 \\
$\mu_{y}$ & 0.0569 & 0.0642 & $\beta_{x x y}$ & 2.0421 & 3.326 \\
$\mu_{z}$ & -0.1506 & -0.1701 & $\beta_{x y y}$ & -3.683 & -20.861 \\
$\mu$ & 1.2107 & 1.3651 & $\beta_{y y y}$ & -0.245 & -3.847 \\
$\alpha_{x x}$ & 68.562 & 78.661 & $\beta_{x x z}$ & 2.604 & 2.108 \\
$\alpha_{x y}$ & 0.356 & 0.433 & $\beta_{x y z}$ & -1.181 & -2.253 \\
$\alpha_{y y}$ & 64.244 & 72.962 & $\beta_{y y z}$ & -2.127 & 9.896 \\
$\alpha_{x z}$ & -4.499 & -5.567 & $\beta_{x z z}$ & 26.384 & 28.784 \\
$\alpha_{y z}$ & 0.176 & 0.191 & $\beta_{y z z}$ & 0.943 & 1.7311 \\
$\alpha_{z z}$ & 54.616 & 62.147 & $\beta_{z z z}$ & 0.694 & 7.089 \\
$\alpha_{0}$ & 62.474 & 71.256 & $\beta_{\text {tot }}(\mathrm{esu})$ & $5.239 \times 10^{-31}$ & $6.124 \times 10^{-32}$ \\
$\alpha$ & 119.39 & 137.01 & & &
\end{tabular}

\subsection{Thermodynamic properties}

On the basis of vibrational analysis, the statically thermodynamic functions: heat capacity $\left(C_{p, \mathrm{~m}}^{0}\right)$, entropy $\left(S_{\mathrm{m}}^{0}\right)$, and enthalpy changes $\left(\Delta H_{\mathrm{m}}^{0}\right)$ for the title molecule are obtained from the theoretical harmonic frequencies and listed in Table VI. From Table VI it can be observed that these thermodynamic functions are increasing with temperature ranging from 100 to $1000 \mathrm{~K}$ due to the fact that the molecular vibrational intensities increase with temperature. The correlation equations between heat capacity, entropy, enthalpy changes and temperatures are fitted by quadratic formulae and the corresponding fitting factors $\left(R^{2}\right)$ for these thermodynamic properties are $0.9997,0.9997$ and 0.9995 , respectively. The corresponding fitting equations are as follows and the correlation graphics of those are shown in Fig. 2.

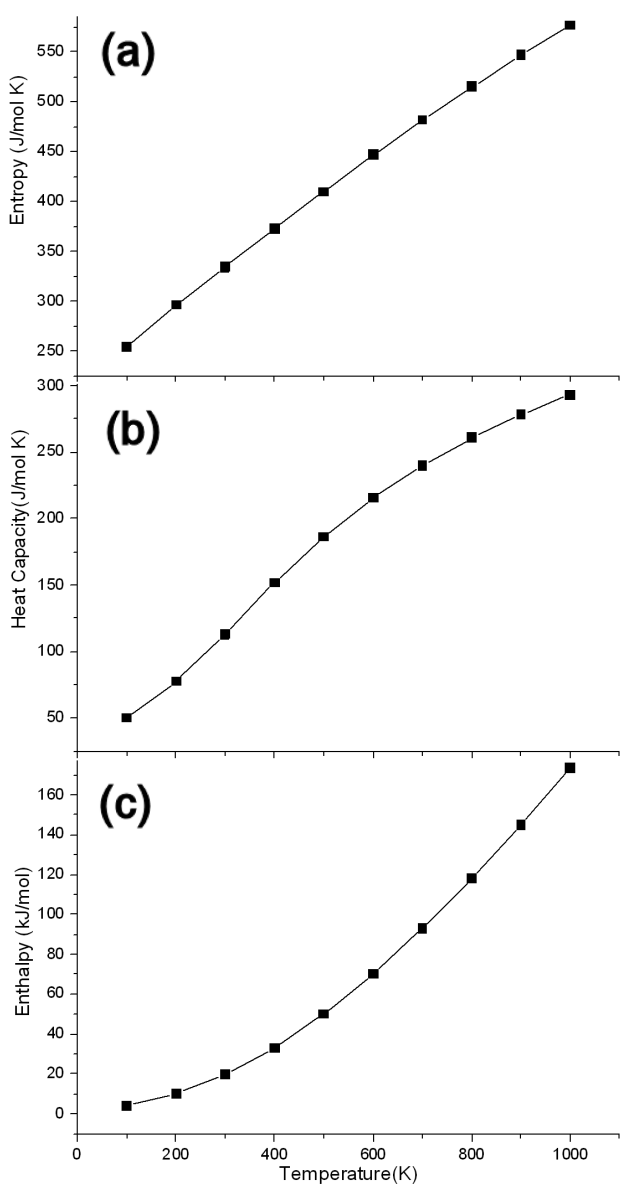

Fig. 2. Correlation graph of (a) entropy and temperature for cyclohexanone, (b) heat capacity and temperature for cyclohexanone, (c) enthalpy and temperature for cyclohexanone.

$$
\begin{aligned}
& C_{p, \mathrm{~m}}^{0}=32.6359+0.5998 T-2.22 \times 10^{-4} T^{2}\left(R^{2}=0.9997\right), \\
& S_{\mathrm{m}}^{0}=32.6359+0.5998 T-2.60 \times 10^{-4} T^{2}\left(R^{2}=0.9997\right), \\
& H_{\mathrm{m}}^{0}=-8.3430+0.0989 T+1.57 \times 10^{-4} T^{2}\left(R^{2}=0.995\right) .
\end{aligned}
$$


All the thermodynamic data supply helpful information for the further study on the cyclohexanone. They can be used to compute the other thermodynamic energies according to relationships of thermodynamic functions and estimate directions of chemical reactions according to the second law of thermodynamics in thermochemical field [21]. Notice: all thermodynamic calculations are done in gas phase and they could not be used in solution.

\section{TABLE VI}

Thermodynamic properties at different temperatures at B3LYP $/ 6-311++G(d, p)$ level for cyclohexanone.

\begin{tabular}{l|c|c|c}
\hline \hline$T[\mathrm{~K}]$ & $S[\mathrm{~J} / \mathrm{mol} \mathrm{K}]$ & $C_{p}[\mathrm{~J} / \mathrm{mol} \mathrm{K}]$ & $\Delta H[\mathrm{~kJ} / \mathrm{mol}]$ \\
\hline 100 & 253.89 & 49.92 & 3.99 \\
200 & 296.46 & 77.5 & 10.29 \\
298.15 & 333.74 & 112.68 & 19.57 \\
300 & 334.44 & 113.39 & 19.78 \\
400 & 372.37 & 151.85 & 33.05 \\
500 & 410.08 & 186.59 & 50.02 \\
600 & 446.77 & 215.91 & 70.18 \\
700 & 481.95 & 240.39 & 93.04 \\
800 & 515.43 & 260.98 & 118.13 \\
900 & 547.21 & 278.45 & 145.13 \\
1000 & 577.34 & 293.37 & 173.74
\end{tabular}

\section{Conclusions}

According to our results the following conclusions are derived for the cyclohexanone.

1. The NBO analysis has provided the detailed insight into the type of hybridization and the nature of bonding in cyclohexanone. The $\sigma(\mathrm{C} 4-\mathrm{H} 12)$ bonds are formed from an $s p^{3.47}$ hybrid on hydrogen atom and $\pi(\mathrm{C} 1-\mathrm{O} 7)$ bond is formed from an $s p^{2.18}$ on oxygen. The strongest electron donation occurs from $\pi(\mathrm{O} 7)$ to $\sigma^{*}(\mathrm{C} 1-\mathrm{C} 2)$ orbitals.

2. The predicted first order hyperpolarizability shows that the molecule might have a reasonably good NLO behavior. The Mulliken atomic charges analysis shows that charge transfer occurs within the molecule. NBO results reflect the charge transfer mainly due to $\mathrm{C}-\mathrm{O}$ group.

\section{References}

[1] W.J. Krasavage, J.L. O'Donoghue, G.D. Divincenzo, in: Patty's Industri Hygiene and Toxicology, Eds. G.D. Clayton, E.E. Clayton, Vol. 2C, 3rd ed., Wiley, New York 1982, pp. 4722, 4780.

[2] M. Windholz, The Merck Index, 10th ed., Merck \& Co., Rahway, NJ 1983, p. 391.

[3] D.M. Considine, Chemical and Process Technology Encyclopedia, McGraw-Hill, New York 1974, p. 337.

[4] Chemcylopedia 87, American Chemical Society, Washington DC 1987, p. 62.

[5] G.G. Hawley, The Condensed Chemical Dictionary, 10th ed., Van Nostrand Reinhold, New York 1981, p. 297.
[6] D.C. Young, Computational Chemistry: A Practical Guide for Applying Techniques to Real World Problems (Electronic), Wiley, New York 2001.

[7] A. Frish, A.B. Nielsen, A.J. Holder, Gauss View User Manual, Gaussian Inc., Pittsburgh, PA 2001.

[8] M.J. Frisch, G.W. Trucks, H.B. Schlegel, G.E. Suzerain, M.A. Robb, J.R. Cheeseman Jr. J.A. Montgomery, T. Vreven, K.N. Kudin, J.C. Burant, J.M. Millam, S.S. Iyengar, J. Tomasi, V. Barone, B. Mennucci, M. Cossi, G. Scalmani, N. Rega, G.A. Petersson, H. Nakatsuji, M. Hada, M. Ehara, K. Toyota, R. Fukuda, J. Hasegawa, M. Ishida, T. Nakajima, Y. Honda, O. Kitao, H. Nakai, M. Klene, X. Li, J.E. Knox, H.P. Hratchian, J.B. Cross, V. Bakken, C. Adamo, J. Jaramillo, R. Gomperts, R.E. Stratmann, O. Yazyev, A.J. Austin, R. Cammi, C. Pomelli, J.W. Ochterski, P.Y. Ayala, K. Morokuma, G.A. Voth, P. Salvador, J.J. Dannenberg, V.G. Zakrzewski, S. Dapprich, A.D. Daniels, M.C. Strain, O. Farkas, D.K. Malick, A.D. Rabuck, K. Raghavachari, J.B. Foresman, J.V. Ortiz, Q. Cui, A.G. Baboul, S. Clifford, J. Cioslowski, B. Stefanov, G. Liu, A. Liashenko, P. Piskorz, I. Komaromi, R.L. Martin, D.J. Fox, T. Keith, M.A. Al-Laham, C.Y. Peng, A. Nanayakkara, M. Challacombe, P.M.W. Gill, B. Johnson, W. Chen, M.W. Wong, C. Gonzalez, J.A. Pople, Gaussian 03, Revision A.I, Gaussian Inc., Pittsburgh 2003, for ref. [8] and [9] compare also Gaussian 09.

[9] P.C. Hariharan, J.A. Pople, Theor. Chim. Acta 28, 213 (1973).

[10] P.C. Hariharan, J.A. Pople, Mol. Phys. 27, 209 (1974).

[11] A.D. Becke, J. Chem. Phys. 98, 5648 (1993).

[12] A.E. Reed, R.B. Weinstock, F. Weinhold, J. Chem. Phys. 83, 735 (1985).

[13] L. Xiao-Hong, L. Xiang-Rua, Z. Xian-Zhou, Comput. Theor. Chem. 969, 27 (2011).

[14] M. Snehalatha, C. Ravikumar, I.H. Joe, N. Sekar, V.S. Jayakumar, Spectrochim. Acta 72A, 654 (2009).

[15] C. James, A. Amal Raj, R. Reghunathan, I.H. Joe, V.S. Jayakumar, J. Raman Spectrosc. $\mathbf{3 7}, 138$ (2006).

[16] J. Liu, Z. Chen, S. Yuan, J. Zhejiang, Univ. Sci. B 6, 584 (2005).

[17] R.K. Roy, K. Hirao, S. Krishnamurthy, S. Pal, J. Chem. Phys. 115, 2901 (2001).

[18] P. Kolandaivel, G. Praveen, P. Selvarengan, J. Chem. Sci. 117, 591 (2005).

[19] C.R. Zhang, H.S. Chen, G.H. Wang, Chem. Res. Chin. U20, 640 (2004).

[20] Y. Sun, X. Chen, L. Sun, X. Guo, W. Lu, Chem. Phys. Lett. 381, 397 (2003).

[21] O. Christiansen, J. Gauss, J.F. Stanton, Chem. Phys. Lett. 305, 147 (1999).

[22] R. Zhang, B. Dub, G. Sun, Y.X. Sun, Spectrochim. Acta A 75, 1115 (2010). 